\title{
Promoção de saúde bucal e Tratamento Restaurador Atraumático sob a ótica de pré- escolares, educadores e pais
}

\author{
Promotion of oral health and Atraumatic Restorative Treatment from the perspective of pre-school, \\ educators and parents \\ Promoción de la salud bucal y tratamiento restaurador atraumático desde la perspectiva de niños en edad \\ preescolar, educadores y padres
}

Recebido: 26/07/2021 | Revisado: 30/07/2021 | Aceito: 02/08/2021 | Publicado: 15/08/2021

Lucimara Cheles da Silva Franzin ORCID: https://orcid.org/0000-0003-3993-8744 Centro Universitário Ingá, Brasil

E-mail: prof.lucimarafranzin@uninga.edu.br

Nathalia de Albuquerque

ORCID: https://orcid.org/0000-0003-3606-4180

Cirurgiã-Dentista, Maringá, Brasil

E-mail: nattialbuquerque23@gmail.com

Josely Emiko Umeda

ORCID: https://orcid.org/0000-0003-1106-4344

Universidade Estadual de Maringá, Brasil E-mail: joumeda@gmail.com

Karina Maria Salvatore Freitas

ORCID: https://orcid.org/0000-0001-9145-6334 Centro Universitário Ingá Uningá, Brasil E-mail: kmsf@uol.com.br

Najara Barbosa da Rocha

ORCID: https://orcid.org/0000-0003-3366-0032

Cirurgiã-Dentista, Maringá, Brasil

E-mail: najara.rocha@gmail.com

Mitsue Fujimaki

ORCID: https://orcid.org/0000-0002-7824-3868 Universidade Estadual de Maringá, Brasil E-mail: mfujimaki@uem.br

\begin{abstract}
Resumo
Recomendações às práticas de promoção da saúde em ambientes coletivos e tratamentos restauradores conservadores representam estratégias na prevenção de doenças bucais desde a infância. Objetivo: Investigar a percepção de préescolares, educadores e pais quanto as recomendações recebidas de estudantes de Odontologia, para a prevenção da doença cárie e uso do Tratamento Restaurador Atraumático (ART) em um Centro de Educação Infantil. Trata-se de um estudo exploratório descritivo observacional com abordagem qualitativa. Realizou-se entrevistas semiestruturadas com 18 crianças de 4 a 5 anos de idade, as atividades lúdico-educativas, cuidados da saúde bucal, escovação supervisionada e Tratamento Restaurador Atraumático. Cerca de 18 educadores e 37 pais responderam um formulário com questões abertas e fechadas sobre promoção da saúde bucal na escola, impacto das atividades educativopreventivas, cuidados com dentes decíduos e uso do Tratamento Restaurador Atraumático. As entrevistas infantis foram transcritas, codificadas e analisadas pela Análise de Discurso, bem como os formulários de educadores e pais. Resultados: A aceitação das crianças quanto à presença do cirurgião-dentista e uso ART foi de $89 \%$. Cerca de $83 \%$ delas associavam a má higienização e a ingestão de alimentos açucarados como desencadeadores da cárie dentária. Quanto aos educadores, $44 \%$ estudaram saúde bucal somente na pós-graduação, mas concordavam sobre a importância do tema na base curricular, para $60 \%$ a cárie era uma doença, e $50 \%$ observaram dor de dente nas crianças. Já $67,5 \%$ dos pais não percebeu cáries nos filhos, e somente 4 observou-lhes dor, no entanto todos concordaram nos efeitos benéficos das atividades educativas/preventivas e uso do ART nas crianças. Conclusões: Os pré-escolares apresentaram compreensão quanto ao conceito de cárie dentária e formas de prevenção, sentiram-se estimulados para o autocuidado, e aceitação ao ART. Educadores e pais observaram que as ações de promoção de saúde bucal e ART no ambiente escolar, promoviam autonomia e empoderamento 'as crianças, gerando-lhes mudanças de comportamento.
\end{abstract}

Palavras-chave: Serviços de saúde escolar; Saúde bucal; Educação em saúde; Cárie dentária; Pré-escolar; Promoção da saúde. 


\begin{abstract}
Recommendations for health promotion practices in collective environments and conservative restorative treatments represent strategies for the prevention of oral diseases from childhood. Objective: To investigate the perception of preschoolers, educators and parents regarding the recommendations received from dental students for the prevention of caries disease and the use of Atraumatic Restorative Treatment (ART) in a Child Education Center. This is an exploratory descriptive observational study with a qualitative approach. Semi-structured interviews were carried out with 18 children from 4 to 5 years of age, educational activities, oral health care, supervised brushing and Atraumatic Restorative Treatment. About 18 educators and 37 parents answered a form with open and closed questions about promoting oral health at school, the impact of educational-preventive activities, caring for primary teeth and the use of Atraumatic Restorative Treatment. The children's interviews were transcribed, coded and analyzed by Discourse Analysis, as well as the forms of educators and parents. Results: The acceptance of children regarding the presence of a dentist and use of ART was $89 \%$. About $83 \%$ of them associated poor hygiene and the intake of sugary foods as triggers of tooth decay. As for educators, $44 \%$ studied oral health only in graduate school, but they agreed on the importance of the topic in the curriculum, for $60 \%$ caries was a disease, and $50 \%$ observed toothache in children. Already $67.5 \%$ of parents did not notice caries in their children, and only 4 reported pain, however all agreed on the beneficial effects of educational/preventive activities and the use of ART in children. Conclusions: Preschool children showed understanding about the concept of dental caries and ways of prevention, felt encouraged to self-care, and accepted ART. Educators and parents observed that actions to promote oral health and ART in the school environment promoted autonomy and empowerment for children, generating changes in their behavior.
\end{abstract}

Keywords: School health services; Oral health; Health education; Dental caries; Prescholler; Health promotion.

\title{
Resumen
}

Las recomendaciones para las prácticas de promoción de la salud en entornos colectivos y los tratamientos restauradores conservadores representan estrategias para la prevención de las enfermedades bucodentales desde la infancia. Objetivo: Investigar la percepción de preescolares, educadores y padres sobre las recomendaciones recibidas de estudiantes de odontología para la prevención de la enfermedad de caries y el uso del Tratamiento Restaurador Atraumático (ART) en un Centro de Educación Infantil. Se trata de un estudio observacional descriptivo exploratorio con abordaje cualitativo. Se realizaron entrevistas semiestructuradas a 18 niños de 4 a 5 años, actividades educativas, cuidado de la salud bucal, cepillado supervisado y Tratamiento Restaurador Atraumático. Alrededor de 18 educadores y 37 padres respondieron un formulario con preguntas abiertas y cerradas sobre la promoción de la salud bucal en la escuela, el impacto de las actividades educativo-preventivas, el cuidado de los dientes primarios y el uso del Tratamiento Restaurador Atraumático. Las entrevistas de los niños fueron transcritas, codificadas y analizadas por Análisis del Discurso, así como las formas de educadores y padres. Resultados: La aceptación de los niños con respecto a la presencia de un dentista y el uso de ART fue del $89 \%$. Alrededor del $83 \%$ de ellos asociaron la falta de higiene y la ingesta de alimentos azucarados como desencadenantes de la caries dental. En cuanto a los educadores, el $44 \%$ estudió salud bucal solo en la escuela de posgrado, pero coincidieron en la importancia del tema en el plan de estudios, para el 60\% la caries era una enfermedad y el 50\% observó dolor de muelas en los niños. Ya el 67,5\% de los padres no notaron caries en sus hijos y solo 4 informaron dolor; sin embargo, todos coincidieron en los efectos beneficiosos de las actividades educativas / preventivas y el uso de TAR en los niños. Conclusiones: Los niños en edad preescolar mostraron comprensión sobre el concepto de caries dental y las formas de prevención, se sintieron motivados al autocuidado y aceptaron el TAR. Educadores y padres observaron que las acciones de promoción de la salud bucal y las ART en el ámbito escolar promovieron la autonomía y el empoderamiento de los niños, generando cambios en su comportamiento.

Palabras clave: Servicios de salud escolar; Salud bucal; Educación en salud; Caries dental; Preescolar; Promoción de la salud.

\section{Introdução}

A cárie dentária é uma doença crônica, multifatorial, prevenível, tendo como principal fator desencadeador o consumo inadequado de açúcares (Lima, 2007; Sheiham \& James, 2015). Apesar do declínio destes índices na população infantil, ainda é o principal problema de saúde bucal na maioria dos países industrializados, e as pessoas sofrem as consequências da falta de resolutividade (Frencken, 2017).

Segundo o estudo da carga global de doenças, 3,9 bilhões de pessoas no mundo ainda são afetadas por doenças bucais, sendo a cárie não tratada na dentição permanente a condição mais prevalente no mundo, entre 291 doenças avaliadas, e a cárie não tratada em dentes decíduos a $10^{\mathrm{a}}$ condição mais prevalente (Marcenes et al., 2013).

No Brasil, segundo dados da Pesquisa Nacional de Saúde Bucal (Brasil, 2010), a prevalência de crianças com dentes cariados, extração indicada e obturados aos 5 anos de idade era de 53,4\%, Nesse contexto, verificou-se a dificuldade de acesso 
da população ao tratamento odontológico, já que cerca de 55\% dos brasileiros não se consultavam anualmente com o dentista (Brasil, 2014). O desafio é contribuir para a redução dos problemas bucais por meio do desenvolvimento de hábitos saudáveis desde a infância (Plutzer \& Spencer, 2008; Gomes et al., 2014), pois sem prevenção a patologia bucal pode evoluir, exigindo intervenções mais complexas, com custos mais elevados, e maiores serão as sequelas.

Assim, há a necessidade de um esforço para atuar com metodologias adequadas para cada faixa etária promovendo o desenvolvimento físico, mental, social, emocional das crianças (Plutzer \& Spencer, 2008) em diversos espaços sociais. As atividades de educação em saúde em instituições para crianças, como Centros de Educação Infantil e escolas, são exemplos de locais apropriados para promoção da saúde nas comunidades (Brasil, 2011), onde podem receber prevenção, e se necessário tratamentos precoces.

A abordagem minimamente invasiva tem sido implementada para promover maior preservação da estrutura dentária. Uma técnica que atende a este conceito, e é economicamente viável para atuação em comunidades tem sido o uso do Tratamento Restaurador Atraumático (ART).

O ART é uma técnica de fácil execução que pode ser realizado fora do ambiente clínico odontológico, com custo inferior ao tratamento odontológico convencional e facilita o acesso dos pacientes ao tratamento (Silvestre, Martins, Silva, 2010). Trata-se de um tratamento restaurador definitivo, desenvolvido em associação com medidas de educação em saúde, realizado com instrumentos manuais e material restaurador adesivo (cimento de ionômero de vidro) (Frencken et al., 2004).

Muitas crianças têm relatado medo e traumas ao tratamento odontológico convencional, além disso, os adultos temerosos ao tratamento têm mostrado baixas condições de saúde bucal. O ambiente dos consultórios (som dos instrumentos rotatórios), relatos de outros pacientes e tempo demasiado na sala de espera podem levar a sensações de desconforto, ansiedade e medo. A conduta do profissional, sem antes mostrar e explicar o procedimento odontológico também pode gerar um comportamento não colaborativo e de negação ao tratamento (Meng et al., 2007).

Contudo, o atendimento realizado dentro do ambiente escolar, observou menor nível de ansiedade nas crianças (Roshan \& Sakeenabi, 2012). O cenário escolar oportuniza às crianças o desenvolvimento da autonomia, participação e criatividade para a promoção da saúde (Iervolino, 2000). Torna-se relevante a discussão e reflexão do empoderamento de conhecimentos pelas crianças e a compreensão de educadores e pais, quanto às ações educativas, preventivas, curativas com pré-escolares.

\section{Objetivo}

O objetivo deste estudo foi investigar a percepção de crianças, educadores e pais com relação às ações de promoção da saúde bucal e Tratamento Restaurador Atraumático, recebidos de estudantes e pós-graduandos de Odontologia, em um Centro de Educação Infantil (CMEI) do sul do Brasil.

\section{Materiais e Métodos}

É um estudo observacional, descritivo e exploratório, de natureza qualitativa. Autorizado pela Secretaria de Educação de Maringá e aprovado pelo Comitê de Ética em Pesquisa com Seres Humanos da Universidade Estadual de Maringá - UEM (CAAE: 58901216.8.0000.0104), seguindo a resolução do Conselho Nacional de Saúde no 466, de 12 de dezembro de 2012.

O estudo foi desenvolvido em um Centro Municipal de Educação Infantil (CMEI), em cidade do sul do Brasil, que atende crianças de 0 a 5 anos de idade, em sua maioria apresentando vulnerabilidade social, dificuldades emocionais e comportamentais. Neste local desenvolveu-se o Projeto Sorrir com Saúde (a cargo de uma instituição de Ensino Pública).

Coletou-se dados dos pré-escolares, educadores e pais das crianças deste CMEI (2016 e 2017). 
Os 18 pré-escolares pesquisados, tinham de 4 a 5 anos de idade, sendo feita amostragem não probabilística intencional ou por julgamento, e o número amostral se deu por saturação teórica. Estas crianças deveriam ter manifestado sinais e sintomas da doença cárie e indicação para o ART, além de possuírem autorização dos pais para participação na pesquisa.

Realizou-se entrevistas orais semiestruturadas (30 minutos) contemplando seis perguntas: atenção odontológica, conceito da cárie dentária e aprendizagem do autocuidado. As entrevistas foram realizadas por duas pesquisadoras no CMEI, em sala reservada. Para as crianças que apresentaram dificuldades para verbalizar seus sentimentos, foram utilizadas imagens de personagens expressando alegria, raiva e tristeza, além de dois desenhos de dentes, sendo um hígido e o outro cariado.

As entrevistas foram transcritas, codificadas e analisadas pela Análise de Discurso. As falas dos pré-escolares foram categorizadas em percepções positivas, negativas e com relação ao seu aprendizado sobre cárie dentária, higienização e alimentação saudável. Os dados quantitativos foram submetidos à análise estatística descritiva.

Os 18 educadores que atuavam com as crianças, foram contactados pela direção do CMEI, e informados dos objetivos da pesquisa. Após aceitarem participar, assinaram um Termo de Consentimento Livre e Esclarecido (TCLE).

A coleta de dados foi realizada de Novembro a Dezembro de 2016, por meio de questionários auto aplicados. Os questionários foram respondidos em sala reservada no CMEI, em momentos de sua conveniência. A confidencialidade dos dados foi assegurada a ambos os grupos pelo pesquisador.

Quanto aos pais, foram convidados aqueles cujos filhos apresentaram lesões de cáries, tratadas na escola pela técnica ART, durante o ano de 2016/2017.

Para os pais, os TCLEs e questionários foram entregues pelos educadores, para preenchimento no domicílio. Foram enviados 45 questionários e obteve-se o retorno de 37.

Realizou-se pesquisa na literatura e elaborou-se a versão final do questionário para educadores e pais com 9 questões fechadas e 9 questões abertas. Constava identificação, conhecimento sobre cárie dentária, cuidados com os dentes decíduos, observação do comportamento infantil antes e após as atividades educativas/preventivas do Projeto, importância da escola para este tipo de atenção, e opinião sobre o ART.

Após a coleta, criou-se um banco no Excel e os dados foram analisados por análise descritiva e pela Técnica do Discurso do Sujeito Coletivo (DSC), que expressa o pensamento dos indivíduos entrevistados, como um conjunto e não uma resposta individual (Lefreve, Lefreve, 2012).

\section{Resultados}

\section{Pré-escolares}

A percepção dos pré-escolares quanto à presença do cirurgião-dentista e atendimento odontológico recebida em âmbito escolar está descrita na Tabela 1. 
Tabela 1 - Distribuição dos pré-escolares quanto à percepção da atenção odontológica no ambiente escolar.

\begin{tabular}{|c|c|c|}
\hline Questões & $\begin{array}{c}\text { Percepções } \\
\text { Positivas }\end{array}$ & Percepções Negativas \\
\hline $\begin{array}{l}\text { 1) O que você sente quando o } \\
\text { dentista te chama para o } \\
\text { atendimento aqui na escola? }\end{array}$ & 16 respostas $(\mathbf{8 9 \%})$ & 2 respostas $(\mathbf{1 1 \%})$ \\
\hline $\begin{array}{c}\text { 2) O que você sente quando o } \\
\text { dentista coloca a 'massinha' (ART) } \\
\text { no seu dente? }\end{array}$ & 14 respostas $(\mathbf{7 8 \%})$ & 4 respostas $(\mathbf{2 2} \%)$ \\
\hline $\begin{array}{l}\text { 3) Você gosta ou não da massinha } \\
\text { (ART) que foi colocada no seu } \\
\text { dente? }\end{array}$ & 16 respostas $(\mathbf{8 9 \%})$ & 2 respostas $(\mathbf{1 1 \%})$ \\
\hline $\begin{array}{l}\text { 4) Como você se sente quando os } \\
\text { dentistas conversam com a sua sala } \\
\text { sobre: escovar os dentes e ter } \\
\text { hábitos saudáveis? }\end{array}$ & 16 respostas $(\mathbf{8 9 \%})$ & 2 respostas $(\mathbf{1 1 \%})$ \\
\hline
\end{tabular}

Fonte: Dados da Pesquisa.

“Eu gosto de vocês (cirurgiões-dentistas), porque vocês cuidam do dente. Eu gosto do dentista na escola. É muito bom quando o dentista me chama para o atendimento". (C13)

Duas crianças (11\%) não se sentiram confortáveis com o atendimento odontológico, relatando experiências traumáticas em visitas anteriores ao cirurgião-dentista, fora do CMEI: "Me sinto triste com o dentista na escola e quando me chamam para atendimento". (C14)

Questionadas sobre o uso da técnica ART, a maioria relatou boa aceitação e segurança durante o procedimento por não apresentar situação dolorosa e resultado estético final.

“É bom, porque não dói o dente”. (C8)

“Eu fico bem quietinha. Eu a acho (massinha) legal. bonita”. (C9)

Uma minoria crianças disse não gostar do ART, justificando não gostar da sensação durante a inserção do material restaurador à base de cimento de ionômero de vidro, devido ao uso da borracha.

“... eu não gosto da massinha, porque quando vocês colocam a massinha, vocês colocam a borracha na minha boca e eu não consigo falar”. (C2)

Em relação à cárie dentária e o autocuidado, estão descritos nas Tabelas 2 e 3. 
Tabela 2 - Distribuição dos pré-escolares quanto ao conceito da cárie dentária.

\begin{tabular}{|c|c|c|}
\hline Questão & $\begin{array}{c}\text { É a destruição localizada dos } \\
\text { tecidos dentais causada pela } \\
\text { ação de bactérias }\end{array}$ & Não soube responder \\
\hline $\begin{array}{c}\text { (5) O que você acha que é a } \\
\text { cárie? }\end{array}$ & 15 respostas $(\mathbf{8 3} \%)$ & 3 respostas $(\mathbf{1 7 \%})$ \\
\hline
\end{tabular}

Fonte: Dados da Pesquisa.

Tabela 3 - Distribuição dos pré-escolares quanto ao autocuidado.

\begin{tabular}{cccc}
\hline Questão & Higiene bucal & Alimentação Saudável & Não soube responder \\
\hline & & & 2 \\
(6) O que você aprendeu com os & 15 & 11 & respostas \\
cirurgiões-dentistas? & respostas & respostas & $\mathbf{( 1 1 \% )}$ \\
\hline
\end{tabular}

Fonte: Dados da Pesquisa.

Exemplos:

"Eu aprendi a comer salada e comer verdura”. (C4)

“Aprendi escovar os dentes, passar fio dental e escovar a língua”. (C8)

"Eu fico feliz e aprendo muito com eles (cirurgiões-dentistas). Eu gosto, eu escovo os dentes na minha casa e aqui”. (C8)

“Me sinto feliz e agora eu como verduras". (C2)

\section{Educadores}

Dados sócio demográficos

Os educadores (n=18) eram todos do gênero feminino, média de idade de 40,8 anos. Em relação a instrução, somente uma profissional não possuía nível superior, com atuação de 2 a 32 anos. 93,45\% eram casadas, com renda variando de 1 a 5 salários mínimos (ano de 2016).

Cerca de 10 educadoras (55,5\%) não havia recebido informações sobre saúde bucal na formação acadêmica, no entanto todas as participantes consideraram relevante a inclusão deste tema no currículo escolar. Quanto ao conceito de cárie dentária $13(72,2 \%)$ consideraram-na uma doença, $3(16,6 \%)$ um buraco no dente e 2 (11\%) uma descalcificação.

Das educadoras, $9(50 \%)$ relataram dor de dente pelas crianças no CMEI, e após a realização do projeto, todas observaram melhora no comportamento infantil, na auto escovação e a perda do hábito de usar a chupeta. 
Pais (dados sócio demográficos)

Em relação aos pais, 29 (70,4\%) eram do sexo feminino e 8 (21,6\%) do masculino, com média de idade de 31,5 anos. Quanto a instrução, a maioria (84\%) havia cursado até o segundo grau, três possuíam o curso superior (8\%). Na área conjugal, $9(24,32 \%)$ mães eram solteiras, 24 casados (64,86\%), 4 amasiados (0,8\%), com renda familiar de 1 a 5 salários mínimos (2016).

Somente 4 pais relataram que a criança apresentou dor de dente em casa durante a alimentação (antes do início do ART), 5 (13,51\%) também visualizaram cárie nos dentes anteriores, devido a alteração da cor. Dos 37 responsáveis, somente $14(37,83 \%)$ havia levado o filho anteriormente a um dentista.

O inquérito sobre a etiologia da cárie está descrito na Tabela 1.29 (78,3\%) perceberam melhora do comportamento da criança em casa, após o início do Projeto e 94,6\% consideraram importante receber informações para a manutenção da saúde bucal de seus filhos.

Tabela 4 - Distribuição dos pais quanto à causa da cárie dentária.

\begin{tabular}{ccc}
\hline Causa da cárie dentária & Pais & \\
\hline Ingestão de doces & $\mathrm{N}$ & $\%$ \\
\hline Falta de escovação/Uso do fio dental & 5 & 13,5 \\
Mamadeira antes de dormir & 4 & 10,81 \\
Amamentação materna & 1 & 2,7 \\
\hline Uso de antibióticos (Infecção) & 1 & 2,7 \\
\hline Não responderam & 1 & 2,7 \\
\hline Total & 25 & 67,56 \\
\hline
\end{tabular}

Fonte: Dados da Pesquisa.

Das 9 questões abertas, a partir das respostas extraiu -se as expressões chaves e ideias centrais de cada indivíduo (Educadoras - E e Pais - P), e posteriormente construiu-se os DSC, emergindo 4 temas principais:

\section{1- Responsabilidade da escola na Promoção da saúde (bucal)}

E: "O suporte da escola é importante para realizar atividades pedagógicas educativas, para a promoção de saúde, e atendimento odontológico das crianças com envolvimento dos pais, pois alguns não se preocupam em cuidar da saúde bucal dos filhos. Faz parte da educação, promove atitudes que leva o indivíduo a cuidar da saúde bucal, nesta fase é mais fácil o aprendizado. Formar adultos conscientes de dentes sempre limpos, higiene bucal diária e adultos com a dentição preservada, o que se aprende com a prática não se esquece".

P: “É muito importante para informar coisas que as vezes não sabemos, tirar dúvidas, estar por dentro do que se passa na saúde da criança e as mães podem cuidar melhor dos dentes e da higiene bucal (dos filhos), porque somos nós pais que ensinamos tudo ou quase tudo que a criança sabe, o que ele aprende de pequeno ele leva pra vida toda. Para nós leigos às vezes passa despercebido alguma coisa que possa prejudicar os dentes permanentes. $\mathrm{Na}$ escola os pequenos aprendem a ter uma boa alimentação e cuidados com a boca."

\section{2- Impacto das atividades educativas e preventivas}

E: "As crianças se preocupam e sentem mais vontade em cuidar dos dentes, pararam com a chupeta, estão mais empolgadas na escovação após as refeições, se sentem importantes e interessadas em uma melhor higiene bucal. Repassam as 
orientações aos pais, e cobram para escovarem seus dentes após as refeições, sem ficar brincando com as escovas no banheiro".

P: "Meu filho aprendeu a cuidar dos dentes, e gosta de escovar, está mais cuidadoso, incentivado, caprichoso. É importante para a educação e orientação da higiene bucal."

\section{3- Cuidados com os dentes decíduos}

E: "Estes cuidados são muito importantes desde tenra idade, uma vez que o hábito de aprender a higiene deve ser estabelecido e mantido por toda a vida. Cuidando dos dentes de leite, tendo boa mastigação as chances de que os permanentes nasçam e se preservem saudáveis são grandes, prevenindo a cárie e males futuros, para saúde de todo o corpo".

P "É importante cuidar dos dentes desde cedo para evitar dor, não ter infecções nos dentes de leite, ter troca normal, estética, quando se tornar adolescente e adulto terão dentes permanentes saudáveis e previne-se problemas de saúde, porque criança também tem autoestima."

\section{4- Atenção curativa pelo ART}

E: "No início do projeto as crianças choravam ao ver pessoas de branco, agora gostam de ser chamadas. Interessante, uma nova forma de atendimento, mais humanizado, não causa traumas a criança, deixa- as tranquilas, mais fácil de incentivalas, com melhor percepção sobre o atendimento odontológico, previne problemas graves. As crianças não veem o aparelho que assusta e o barulho, se familiarizam com o ambiente e se tornam menos agressivas, sentem mais confiança, no futuro não terão traumas para ir ao dentista."

P "É um meio simples, que resolve o problema dentário, ajuda a perder o medo do dentista, a criança se sente mais à vontade. Com esse tratamento vai ter menos crianças com problemas odontológicos. Eles ficam felizes em ir ao dentista, e orgulhosos de si mesmos. Nem todos tem acesso ao dentista".

\section{Discussão}

\section{Pré-escolares}

Muitas crianças têm relatado medo e traumas no tratamento odontológico, e adultos temerosos ao tratamento têm mostrado baixas condições de saúde bucal. O ambiente dos consultórios (instrumentais pontiagudos, som dos instrumentos rotatórios), relatos de outros pacientes e tempo demasiado na sala de espera podem levar a sensações de desconforto, ansiedade e medo. O modo de agir do profissional, sem antes mostrar e explicar o procedimento odontológico também pode gerar um comportamento não colaborativo e de negação ao tratamento (Meng et al., 2007). Contudo, quando o atendimento é realizado dentro do ambiente escolar foi verificado menor nível de ansiedade nas crianças (Roshan \& Sakeenabi, 2012). Semelhantemente nos pré-escolares estudados observou-se a aceitação quanto à presença do cirurgião-dentista e o atendimento em âmbito escolar se mostrou positiva para a maior parte deles.

Considerando-se o desenvolvimento da cárie dentária, e as perspectivas de técnicas restauradoras minimamente invasivas e preventivas (Schwendicke et al., 2018) o Tratamento Restaurador Atraumático (ART) é uma alternativa para sua interrupção (Hesse, 2015). Indicado para crianças de alto risco, lesões iniciais de cárie com cavidades ou não em esmalte (selamento terapêutico), restaurador (Navarro et al., 2015) Esta técnica reduz custos quando comparada aos tratamentos restauradores convencionais, é de fácil execução e eficácia (Silva et al. , 2012) reduz o tempo clínico, diminui a sintomatologia dolorosa, sendo uma boa alternativa para todas as faixas etárias, no âmbito clínico privado e público (Smales, 2000). Previamente ao ART, deve se promover a educação e promoção de saúde à criança, através da instrução de higiene bucal e dieta saudável, obtendo-se um enfoque preventivo e terapêutico, e não apenas restaurador (Navarro et al., 2015). Neste sentido 
os projetos odontológicos educativos nas escolas (Projeto Sorrir com Saúde, da Universidade Estadual de Maringá (UEM) realizado com pré-escolares e escolares) trabalham a promoção de saúde, fundamentado na educação e prevenção para a saúde bucal e intervenções clínicas como selantes, aplicação tópica de fluoretos e uso do ART.

Segundo a opinião dos pré-escolares entrevistados, houve concordância com respeito à má higienização e ingestão de alimentos não saudáveis associados às bactérias como sendo desencadeadores da cárie dentária. Esta doença resulta de desequilíbrios causados por hábitos inadequados como alimentação rica em sacarose, higienização bucal deficiente, falta de visitas regulares ao cirurgião-dentista, portanto a falta de informação implicará possivelmente em seu desenvolvimento e de outras patologias. Assim, os pontos de vistas dos entrevistados entraram em concordância com a literatura sobre o assunto (Lopez, Simpser-Rafalin, Berthold, 2005).

No entanto uma pequena porcentagem (17\%) dos entrevistados não soube responder adequadamente ao conceito de cárie dentária, apesar de ter recebido como todos os demais, pela educação em saúde. O que pode ser explicado pelos níveis diferentes de aprendizagem e assimilação que as crianças possuem (Watt $\left.{ }^{2}, 2005\right)$.

Quanto ao questionamento aos pré-escolares em relação ao entendimento sobre o autocuidado, decorrente de todo o trabalho de prevenção de doenças bucais, promoção em saúde e atividades reabilitadoras atraumáticas recebidos, os entrevistados se mostraram felizes e aprovaram as atividades desenvolvidas durante a educação em saúde, pois aprenderam a escovar os dentes e utilizar o fio dental para uma higienização mais completa, além de melhorar a sua alimentação. Estes resultados concordam com a literatura, que elucida que o resultado da educação em saúde bucal é significativo quando o indivíduo assimila as informações repassadas por meio das atividades lúdicas como: narração de histórias temáticas, jogos e brincadeiras em associação com a escovação supervisionada. Desta forma, a educação em saúde realizada através do planejamento e se as atividades estão em conformidade com as necessidades do público assistido, isso leva à melhoria nas condições de saúde por meio da adoção de práticas adequadas para a manutenção de saúde bucal (Watt, 2005).

Além disso, observou-se que as crianças processarem os ensinamentos e disseminarem os conhecimentos adquiridos em suas casas e comunidades. De acordo com as respostas obtidas, a maioria dos pré-escolares foram sensibilizados a adquirirem hábitos saudáveis tanto por meio da escovação dos dentes, como formas adequadas de alimentação saudável, levando assim, à prevenção de doenças. Em concordância com a literatura, as intervenções educativas lúdicas em ações de promoção de saúde bucal, realizadas com pré-escolares de instituições de educação infantil, são efetivas para a aquisição de hábitos saudáveis e desenvolvimento de habilidades para o autocuidado (Sigaud et al., 2017).

Alguns autores reforçam também a necessidade de desenvolvimento de mais programas de educação em saúde bucal voltados para a população infantil devendo ser cuidadosamente elaborados com diagnóstico situacional prévio, levando-se em conta, não só a idade de seus participantes, como também sua realidade social, econômica e cultural (Ferrazzano et al., 2008).

Além disso, a educação em saúde bucal poderia ser integrada à educação para a saúde geral dentro do contexto pedagógico da escola, com a tomada de decisão por opções saudáveis na alimentação rica em verduras, legumes, cereais e frutas, e redução da ingestão de alimentos industrializados ricos em açúcar (sacarose), complementados por higienização dental e o uso do fio dental, estimulados para incorporarem à rotina diária (Ferrazzano et al., 2008; Santos et al., 2017).

\section{Educadores e pais}

Escola promotora de saúde: Educadoras e pais compreendiam o papel da escola como promotora de saúde. O ambiente escolar reúne crianças em faixas etárias propícias a aquisição de hábito saudáveis, a fim de se obter alterações do processo saúde-doença. De acordo com Stillman- Lowe (2008) as orientações de saúde bucal devem ser claras, precisas e inequívocas. 
E: Das 18 educadoras, 55,5\% não havia recebido informações sobre saúde bucal. Achados também encontrados por Torres (2002) avaliando educadores, concluiu que os atores sociais da escola e da saúde, devem trabalhar em conjunto para o desenvolvimento de habilidades de autocuidado em saúde, e prevenção das condutas de risco em todas as oportunidades educativas.

Neste estudo embora grande parte das educadoras não tivessem formação em saúde bucal, reconheciam a importância da escola para complementação do processo educativo das crianças, e os profissionais de Odontologia como fonte destas informações. Em concordância, para Arciere (2013) esta complementação é necessária para uma capacitação ativa e colaborativa nas ações de prevenção e promoção de saúde, pois os professores exercem influência sobre o comportamento das crianças, pelo contato diário por longo tempo.

P: A maioria dos pais se mostrou receptiva e interessada em receber informações na escola, para a saúde bucal dos filhos.

Para Souza et al. (2015) o compartilhamento de informações sobre saúde bucal com educadores, em oficinas na Rede Pública de Patos (PB), capacitou-os para que o tema estivesse no cotidiano das escolas.

Outro estudo avaliando pais na Paraíba observou que 100\% se mostraram receptivos a informações sobre saúde bucal. Como as crianças dependem diretamente da supervisão dos pais, a disseminação destas informações poderia ocorrer por meio da escola (Massoni, Forte, Sampaio, 2005).

Ao inquérito da etiologia da cárie dentária nos filhos, $67,56 \%$ dos pais não respondeu, e uma minoria (27,01\%) associou a dieta açucarada à falta de higiene antes de dormir, como sendo as responsáveis. Em concordância, estudo com crianças de uma Clínica Odontológica Preventiva na Paraíba, os pais consideravam o controle mecânico do biofilme (escovação e fio dental) mais relevantes que os cuidados com a dieta, como forma de prevenção da cárie (Massoni, Forte, Sampaio, 2005).

Talvez estes dados, justifiquem a grande ausência de respostas pertinentes à etiologia da cárie no presente estudo, sugerindo uma possível desinformação dos pais sobre o tema, o que poderia ter influenciado na dificuldade de prevenir a doença.

Estudo qualitativo investigando as percepções de professores e pais, de escolas públicas do País de Gales, de diferentes níveis socioeconômicos, concluiu unanimidade dos pais quanto a responsabilidade da saúde bucal estar sob o domínio dos progenitores, que embora expressassem ser o açúcar prejudicial e haver necessidade de sua redução, na prática havia pouca consciência perceptível, em especial na escola de nível social mais baixo, onde havia índices elevados de cárie dentária, realçando a diferença entre a prática e o discurso (Richards, Coll, Filipponi, 2017).

Neste estudo, os pré-escolares apresentaram atividade da doença cárie, com manifestações clínicas que poderiam comprometer sua saúde e aprendizagem. Os educadores compreendiam a importância de abordar as famílias a coresponsabilidade do cuidado com a saúde, mas este diálogo ainda não tinha ocorrido. Por outro lado, apesar dos pais terem interesse em entender melhor as doenças bucais, sugeriam um conhecimento limitado sobre o tema. Assim a interação dos profissionais de saúde no ambiente escolar se faz oportuna para apoiar este processo educativo.

Segundo Watt (2007) uma vez que os usuários nem sempre têm acesso aos serviços de saúde, os grupos de risco às doenças bucais necessitam receber abordagens alternativas em outros espaços sociais como nas escolas, sendo relevante a inclusão de outros profissionais para ações eficazes. As "escolas saudáveis" trabalham de maneira integrada os conteúdos de saúde e a prática no dia a dia, trabalhando o desenvolvimento integral da criança.

Os educadores pesquisados relataram a necessidade de atividades pedagógicas interativas com os profissionais da saúde e envolvimento da família. 
As metas do Programa Saúde na Escola (PSE) relatam a importância do agendamento e preparo prévio dos educandos sobre as atividades em saúde a ser realizadas e desenvolvidas de forma interdisciplinar, estando relacionadas com o momento pedagógico e conteúdo que os alunos estejam trabalhando $\left({ }^{23}\right.$.

Estudo avaliando a aquisição e o conhecimento de saúde bucal por professores de uma Escola Pública de Belo Horizonte- MG relataram a importância da escola para a incorporação dos conceitos de saúde e higiene bucal, a fim de difundilos em sala de aula. Para isto os professores sugeriram formas de integração com os cirurgiões dentistas em debates, oficinas, grupos de discussão, palestras, congressos, além do desenvolvimento de projetos pedagógicos. Estes autores encontraram alta escolaridade entre os professores participantes, no entanto 56\% nunca tinham estudado saúde bucal na sua formação, com confusão de conceitos sobre o papel da pasta de dente, fio dental, alimentos favoráveis e desfavoráveis aos dentes e flúor. A alta escolaridade das educadoras no presente estudo pode justificar a adesão e aceitação de $100 \%$ na inclusão do tema no currículo escolar (Vasconcelos et al., 2001).

A interação profissionais-educadores-núcleo familiar é importante para que hábitos saudáveis ainda não adquiridos possam ser implementados, e acompanhados para estimular a prática do autocuidado

Impacto das atividades educativas e preventivas na escola: Os educadores observaram que após as atividades lúdicoeducativas e escovação supervisionada as crianças ficaram mais atentas e motivadas para sua higiene bucal, cobrando-a dos educadores e atuando como possíveis multiplicadores das informações aos pais. Também, aquelas que possuíam hábito deletério da chupeta, cessaram seu uso. Relatos também ratificados pelo grupo de pais nas atividades de saúde bucal no domicílio.

Salienta-se a relevância da prevenção das doenças bucais desde a infância, como a doença cárie a fim de se evitar prejuízos ao bem estar do indivíduo. Pesquisas recentes (Brasil, 2012; CDHS., 2015) demonstram ao longo dos anos um declínio na prevalência da doença cárie, no entanto ainda persiste em grupos de risco, na Europa e no Brasil. No último levantamento epidemiológico de saúde bucal no Brasil (SB 2010), ano de 2010 constatou-se que 53,4\% das crianças na faixa etária de 5 anos apresentavam pelo menos um dente decíduo com experiência da doença cárie (Brasil, 2012). As possíveis sequelas são diminuição do apetite, dificuldade na mastigação e perda de peso, dificuldade para dormir, alteração de comportamento (baixa autoestima e irritação) além de baixa no rendimento escolar (Assumpção Júnior, et al., 2000).

Souza et al. (2015) abordando a família, educadores e crianças do Ensino Público de Patos (PB) com ações de práticas de promoção em saúde e uso do ART, observou melhoras na saúde bucal, e autonomia para a criação de agentes multiplicadores de saúde.

As atividades lúdico-educativas, escovação supervisionada do Projeto Sorrir com Saúde se mostraram altamente aplicáveis e passíveis de serem incorporadas no ambiente escolar por propiciarem aceitação e resultados satisfatórios. A continuidade das atividades educativas é necessária, isto se faz de maneira lenta, mas uma vez ocorrido este empoderamento, se estabelecem por toda a vida.

Cuidados com os dentes decíduos: Todas as educadoras e 11 (29,72\%) pais reforçaram a relevância dos cuidados com os dentes decíduos para se ter dentes permanentes íntegros. No entanto 14 (37,83\%) pais relataram esta importância sem justificar a razão, $4(10,81 \%)$ citaram para uma boa saúde bucal, 3 (8,10\%) pela estética e autoestima da criança, 2 ocorrências de infecção e dor no decíduo, enquanto $3(8,10 \%)$ não responderam.

Estudos mostraram a relevância dos cuidados dispensados aos dentes decíduos, que embora temporários, são essenciais nas funções de mastigação, fonética, e oclusão do indivíduo, devendo ser preservados até esfoliar naturalmente (Alencar, Cavalcante, Bezerra, 2007; Souza et al., 2015). Drumond, Meldrum, Boyd (2013) citaram que os problemas dentários da primeira infância podem proporcionar efeito negativo na saúde bucal e qualidade de vida infantil, exteriorizando-o a sua família. 
Em concordância, neste estudo foi unânime para educadores e pais a percepção da relevância dos cuidados com os dentes decíduos, estando fortemente integrada 'as contribuições para a prevenção dos dentes permanentes.

Uso do ART: As educadoras e pais relataram que a técnica era interessante, atraumática, deixava as crianças mais tranquilas, menos agressivas, aceitando e tendo um novo olhar para o atendimento odontológico, com reflexos na sua qualidade de vida. Estudo em programas para pré-escolares, concluiu que o ART pode contribuir na redução de complexos tratamentos invasivos, que exigem uma colaboração maior do paciente, além da atenção de especialistas (Navarro et al., 2015).

No Brasil, estudos avaliando a percepção dos pais, em relação ao uso da técnica ART nos filhos, observaram uma alta aprovação principalmente por ser atraumático, indicando-o a outros progenitores (Raggio et al. 2004; Mandarino, Miasato, Mandarino, 2009; Knirsch et al., 2010).

Em Teresópolis - RJ, numa comunidade da Pastoral da criança, estudo com 34 pais observou satisfação de $94,1 \%$ pela técnica. Os motivos da preferência foram o carinho dos cirurgiões-dentistas, diminuição do medo da frente ao atendimento criança sem medo e a gratuidade. Enfatizaram o ART sendo uma filosofia moderna, indolor, com deteç̧ão precoce e interceptação da doença por meio de uma restauração preventiva. Em relação à adesão e colaboração das crianças ao uso do ART, pesquisa ${ }^{18}$ com 5 crianças na Paraíba, observou comportamento colaborador (Mandarino, Miassato, Mandarino, 2009)

Navarro et al. (2015), baseando-se em revisões sistemáticas e meta-análises citaram que a propensão ao medo geralmente está associada à agulha da anestesia local, e ao barulho do aparelho de alta-rotação, assim o ART é uma excelente opção no manejo do comportamento de pacientes infantis e/ou ansiosos, ao utilizar apenas instrumentos manuais, e raramente fazer uso da anestesia local em cavidades na dentina, contribuindo para reduzir os tratamentos invasivos complexos. Em concordância com Kikwilu et al. (2009) citando como relevância do ART a ausência das anestesias, brocas e a flexibilidade de realização em locais fora do consultório odontológico como em escolas. Esta técnica impacta e disponibiliza a acessibilidade às crianças com maior risco e necessidade, evitando traumas futuros, uma problemática enfrentada pelos pais (Raggio et al., 2004).

No presente estudo $62,16 \%$ dos pais não tinham buscado um dentista embora as crianças apresentassem cárie dentária e algumas delas dor, $25(67,56 \%)$ relataram não a ter observado, até receberem o aviso na agenda. Esses achados corroboram com o estudo de Mandarino et al. (2009) cujas crianças (73,5\%) só tiveram acesso ao dentista por meio da Pastoral, relacionando estes dados à pouca condição socioeconômica dos participantes, despreparo e falta de conhecimento das mães, concluindo que pais de menor nível socioeconômico tendem a buscar o tratamento da cárie para tratar a lesão e não a prevenir.

Neste trabalho, a maioria das crianças eram provenientes de origens sócio econômicas baixas, o que pode ter contribuído para o despreparo da prevenção da saúde bucal, concordando com o estudo de Piovesan et al. (2010). No entanto, Aquilante (2015) citou que os profissionais da saúde devem ter cautela ao responsabilizarem os usuários pelos problemas de saúde que apresentam, uma vez que estas estão ligadas a determinantes sociais (falta de acesso aos serviços de saúde, desnutrição, custos dos alimentos, dentre outros).

Massoni, Forte, Sampaio (2015) citaram haver pouca divulgação do ART na área de saúde pública, sugerindo o desconhecimento da técnica entre os profissionais, operacionalidade, e sua eficácia.

Os educadores e pais pesquisados mostraram aprovação pelo método de tratamento utilizado pelos estudantes para o controle da cárie.

Embora o discurso não signifique o pensamento do todo, sugere-se que a discussão entre educadores e pais promoverá um entendimento maior sobre a saúde bucal, estendendo-o às crianças, a fim de que adotem e incorporem hábitos saudáveis. 


\section{Considerações Finais}

Conclui-se que a maior parte das crianças apresentou boa compreensão em relação à cárie dentária e suas formas de prevenção, tendo sido estimuladas para o autocuidado e aquisição de hábitos saudáveis, não apenas no âmbito da saúde bucal, mas também à saúde geral.

As atividades lúdico-educativas contribuíram para maior compreensão do processo saúde-doença e a presença do cirurgião-dentista dentro do ambiente escolar favoreceu maior aceitação e colaboração das crianças para o uso de técnicas menos invasivas, como o ART.

Os educadores e pais também observaram impactos positivos sobre as atividades educativas e preventivas realizadas, observando mudança de comportamento nas crianças, que se tornaram mais cuidadosas com a higiene bucal e cessaram o uso da chupeta. Os participantes compreendiam a importância da preservação e manutenção dos dentes decíduos, para preservação dos dentes permanentes contribuindo para a saúde geral, e se posicionaram favoráveis ao uso da técnica do ART nas crianças, pela efetividade, ser atraumático, por promover aceitação ao tratamento odontológico, e ser de fácil acesso.

As percepções positivas dos três grupos em relação programas e atividades dessa natureza em ambiente escolar sinalizam que devam ser contínuos, a fim de desenvolver habilidades que reflitam na saúde bucal, e geral dos indivíduos.

\section{Agradecimentos}

As Secretarias Municipais de Educação e Saúde de Maringá, aos funcionários do Centro Municipal de Educação Infantil - Nilza de Oliveira Pipino em especial 'as educadoras e familiares (pais) das crianças que participaram do Projeto Sorrir com Saúde. Aos docentes, alunos da graduação e pós-graduação da UEM, envolvidos no Projeto Sorrir com Saúde.

\section{Referências}

Alsheneifi, T., \& Hughes, C. V. (2001) Reasons for dental extractions in children. Pediatric Dentistry, $23(2), 109-112$.

Brasil, IBGE - Instituto Brasileiro de Geografia e Estatística. Pesquisa nacional por amostra de domicílios 2003. Brasília, 2005. <http://www.ibge.gov.br/home/presidencia/noticias/noticia_visualiza.php?id_noticia=370\&id_pagina=1>.

Brasil, IBGE - Instituto Brasileiro de Geografia e Estatística. Pesquisa Nacional de Saúde 2013: Percepção do estado de saúde, estilos de vida e doenças crônicas: Brasil, Grandes Regiões e Unidades da Federação. Rio de Janeiro, $2014 . \quad<$ http://bvms.saude.gov.br/bvs/publi cacoes/passo_a_passo_programa_saude_escola.pdf>.

Brasil. Ministério da Saúde. Passo a Passo do Programa Saúde na Escola (PSE). Brasília: Ministério da Saúde, 2011.<http://bvms.saude.gov.br/bvs/publicacoes/passo_a_passo_programa_saude_escola.pdf >.

Ferrazzano, G. F., Cantile, T., Sangianantoni, G., \& Ingenito, A. (2008) Effectiveness of a motivation method on the oral hygiene of children. European Journal of Paediatric Dentistry, 9, 183-187.

Figueiredo, K. S. P., Forte, F. D. S., \& Sampaio, F. C. (2008) Desempenho clínico de Restaurações ART (Tratamento Restaurador Atraumático) em crianças atendidas na clínica de cariologia da UFPB. Revista de Odontologia da UNESP, 37(4): 351-355.

Frencken, J. E., Van’t Hof, M. A., Van Amerongen, W. E., \& Holmgren, C. J. (2004) Effectiveness of single-surface ART restorations in the permanent dentition: a meta-analysis. Journal of Dental Research, 83(2): 120-123.

Gomes, M. C., Pinto-Sarmento, T. C., Costa, E. M., Martins, C., Granville, C., Garcia, A. F., \& Paiva, S. M. (2014) Impact of oral health conditions on the quality of life of preschool children and their families: a cross-sectional study. Health Qual Life Outcomes, 18:12, 55.

Lima, J. E. O. (2007) Cárie dentária: um novo conceito. Revista Dental Press de Ortodontia e Ortopedia Facial, 12(6), 119-130.

Lopez, N., Simpser-Rafalin, S., \& Berthold, P. (2005) Atraumatic Restorative Treatment for prevention and treatment of caries in an underserved community. American Journal of Public Health, 95, 1338-1339.

Marcenes, W., Kassebaum, N. J., Bernabé, E, Flaxman, A., Naghavi, M., Lopez, A., \& Murray, C. J. L. (2013) Global burden of oral conditions in 1990-2010: a systematic analysis. Joutnal of Dental Research, 92(7), 592-597.

Meng, X, Heft, M. W., Bradley, M. M., \& Lang, P. J. (2007) Effect of fear dental utilization behaviors and oral health outcome. Community Dentistry and Oral Epidemiology, 35(4): 292-301.

Oliveira, J. C. C. (2014) Atividades lúdicas na Odontopediatria: uma breve revisão da literatura. Revista Brasileira de Odontologia, 71 (1), $103-107$. 
Research, Society and Development, v. 10, n. 10, e134101018726, 2021

(CC BY 4.0) | ISSN 2525-3409 | DOI: http://dx.doi.org/10.33448/rsd-v10i10.18726

Orlandi, E. P. (1999) Análise de discurso: princípios e procedimentos. Pontes.

Plutzer, K., \& Spencer, A. J. (2008) Efficacy of an oral health promotion intervention in the prevention of early childhood caries. Community Dentistry and Oral Epidemiology, 36(4), 335-346.

Ramos-Jorge, M. L., \& Paiva, S. M. (2003) Comportamento Infantil no Ambiente Odontológico: Aspectos Psicológicos e Sociais. Jornal Brasileiro de Odontopediatria e Odontolia de Bebês, 6, 70-74.

Roshan, N. M., \& Sakeenabi, B. (2012) Anxiety in Children during occlusal ART restorations in primary molars placed in school environment and hospital dental setup. Journal of Clinical and Pediatric Dentistry, 36: 349-352.

Santos, S. P., Vieira, G. O., Scavuzzi, A. I. F., \& Gomes Filho, I. S. (2016) Práticas alimentares e cárie dentária - uma abordagem sobre a primeira infância. Revista da Associação Paulista de Cirurgiões Dentistas, 70(1), 12-18.

Sheiham, A., \& James, W. P. T. (2015) Diet and Dental Caries: The Pivotal Role of Free Sugars Reemphasized. Journal of Dental Research, 94(10), 1341-7.

Sigaud, C. H. S., Santos, B. R., Costa, P., \& Toriyama, A. T. M. (2017) Promoção de higiene bucal de pré-escolares: efeitos de uma intervenção educativa lúdica. Revista Brasileira de Enfermagem, 70(3), 545-551.

Silvestre, J. A. C., Martins, P., \& Silva, J. R. V. (2010) O tratamento restaurador atraumático da cárie dental como estratégia de prevenção e promoção da saúde bucal na estratégia saúde da família. Sanare, 9(2), 81-85.

Singh, K. A., Moraes, A. B. A., \& Ambrosano, G. M. B. (2000) Medo, ansiedade e controle relacionados ao tratamento odontológico. Pesquisa Odontológica Brasileira, 14(2), 131-136.

Wan, H. et al. (1999) Atraumatic restorative treatment fillings and fissure sealant in permanent teeth - a 2-year study. Hua Xi Kou Qiang - Yi Xue Za Zhi, $17(1), 42-45$.

Watt, R. G. (2005) Strategies and approaches in oral disease prevention and health promotion. Bulletin of the World Health Organization, 83(9), 711-718.

Watson, M. R. et al. (2001) A community participatory oral health promotion program in an Inner-city Latino community. Journal of Public Health Dentistry, 61(1), 34-41. 